Article

\title{
Humanities for the Environment-A Manifesto for Research and Action
}

Poul Holm ${ }^{1, *}$, Joni Adamson ${ }^{2}$, Hsinya Huang ${ }^{3}$, Lars Kirdan ${ }^{4}$, Sally Kitch ${ }^{5}$, Iain McCalman ${ }^{6}$, James Ogude ${ }^{7}$, Marisa Ronan ${ }^{1}$, Dominic Scott ${ }^{8}$, Kirill Ole Thompson ${ }^{9}$, Charles Travis ${ }^{1}$ and Kirsten Wehner ${ }^{10}$

1 School of Histories and Humanities, Trinity College Dublin, 2 College Green, Dublin 2, Ireland; E-Mails: ronanm@tcd.ie (M.R.); travisc@tcd.ie (C.T.)

2 Department of English, College of Liberal Arts and Sciences, Arizona State University, Tempe, AZ 85281, USA; E-Mail: joni.adamson@asu.edu

3 Department of Foreign Languages and Literature, National Sun Yat-sen University, 70 Lien-hai Road, Kaohsiung 804, Taiwan; E-Mail: hsinya@mail.nsysu.edu.tw

4 SAS Institute, Købmagergade 7-9, 1150 Copenhagen K, Denmark; E-Mail: lars@kirdan.dk

5 Institute for Humanities Research, Arizona State University, Social Sciences Building Room 107, PO Box 876505, Tempe, AZ 85287-6505, USA; E-Mail: Sally.Kitch@asu.edu

6 Department of History, D17—Charles Perkins Centre, The University of Sydney, Sydney 2006, NSW, Australia; E-Mail: iain.mccalman@usyd.edu.au

7 Centre for the Advancement of Scholarship, University of Pretoria, Private bag X20, Hatfield 0028, South Africa; E-Mail: James.Ogude@up.ac.za

8 Faculty of Philosophy, Radcliffe Humanities, Radcliffe Observatory Quarter, University of Oxford, Woodstock Road, Oxford OX2 6GG, UK; E-Mail: dominic.scott@philosophy.ox.ac.uk

9 Institute for Advanced Studies in Humanities and Social Sciences, National Taiwan University, No.1, Sec.4, Roosevelt Road, Taipei 10617, Taiwan; E-Mail: ktviking@gmail.com

10 National Museum of Australia, GPO Box 1901, Canberra ACT 2601, Australia; E-Mail: kirsten.wehner@nma.gov.au

* Author to whom correspondence should be addressed; E-Mail: holmp@tcd.ie; Tel.: +353-1896-2593.

Academic Editor: Albrecht Classen

Received: 22 October 2015 / Accepted: 13 December 2015 / Published: 21 December 2015

Abstract: Human preferences, practices and actions are the main drivers of global environmental change in the $21 \mathrm{st}$ century. It is crucial, therefore, to promote pro-environmental behavior. In order to accomplish this, we need to move beyond rational 
choice and behavioral decision theories, which do not capture the full range of commitments, assumptions, imaginaries, and belief systems that drive those preferences and actions. Humanities disciplines, such as philosophy, history, religious studies, gender studies, language and literary studies, psychology, and pedagogics do offer deep insights into human motivations, values, and choices. We believe that the expertise of such fields for transforming human preferences, practices and actions is ignored at society's peril. We propose an agenda that focuses global humanities research on stepping up to the challenges of planetary environmental change. We have established Environmental Humanities Observatories through which to observe, explore and enact the crucial ways humanistic disciplines may help us understand and engage with global ecological problems by providing insight into human action, perceptions, and motivation. We present this Manifesto as an invitation for others to join the "Humanities for the Environment" open global consortium of humanities observatories as we continue to develop a shared research agenda.

Keywords: humanities for the environment; global change; observatories

\section{Background}

"Environmental humanities" is a rapidly developing research field that involves tens of thousands of researchers globally and is currently organized into diverse disciplinary associations for the study of literature, art, history, and philosophy of the environment. It is, however, extremely difficult to get an overview of what is happening, let alone to promote a dialogue between the anarchic world of academia and the stakeholders of global change [1,2]. The Humanities for the Environment initiative is an innovative effort to promote such a dialogue and to bridge disciplinary gaps in the pursuit of effective approaches to environmental challenges.

The Humanities for the Environment (HfE) Observatories were initiated under the auspices of a two-year pilot grant from the Andrew W. Mellon Foundation. The observatories began operation in 2013 as part of a larger program entitled Integrating the Humanities Across National Boundaries, awarded to the Consortium of Humanities Centers and Institutes (CHCI), which has a membership of over 180 humanities centers and institutes globally. All the Observatories pursued a common question: What is the role of the humanities in the age of the Anthropocene? The initial group brought together humanities centers on three continents, North America (Arizona State University, Wake Forest University and Clark University), Europe (Trinity College Dublin), and Australia (University of Sydney). Each Observatory included community, corporate, NGO, governmental and academic partners. The aim was to identify, explore, and demonstrate the contributions that humanistic and artistic disciplines could make to stir wider awareness and understanding and more efficacious engagement with global environmental challenges.

The grantees chose the word "Observatories" to indicate that the award would not monopolize resources through narrow centers, but would, rather, observe broadly and reach out to map and work with the many new environmental humanities initiatives developing regionally and around the world. 
As a descriptive term, "Observatory" was chosen to quicken the imagination of humanists being called upon to think outside the limitations of traditional humanities research protocols.

Our aim was, first, to map and expand ongoing projects and activities in the home regions; second, to develop linkages, networks and new research questions and outcomes; and third, to begin a transformative process that would test new models for humanities outcomes, public engagement, policy formulation, and pedagogical impact. As the process evolved, each observatory selected appropriate themes, including: Environmental Sustainability and Social Justice (North America); The New Human Future (Europe); Caring for Country (Australia). Over time, new Observatories in East Asia (National Taiwan University, Academia Sinica, National Sun Yat-sen University, and National Chung-Hsing University) and Africa (the University of Pretoria) joined the initiative. The research manifesto presented here is an outcome of this expansion process.

We recognize that science is able to monitor, measure and to some extent predict the biogeophysics of global change. However, its analytical power stops short of investigating the main driver of planetary change - the human factor. What humans believe and value, how we organize ourselves, and what we invest to achieve our goals are factors that lie largely outside scientific calculation. We are not alone in advocating the need for collaboration between the human, social and natural sciences. International scientific organizations have issued strong calls for the inclusion of the humanities in programs of global environmental research. Such calls have been voiced by a series of major international science conferences and sponsorships, such as:

- Challenges of a Changing Earth: Global Change Open Science Conference held in Amsterdam in July 2001

- European Science Foundation Forward Look 2002

- International Council for Science Visioning process 2009

- International Council for Science "new initiative" 2011

- European Science Foundation-COST RESCUE 2011-2012

- Future Earth, 2013-2023

The agreement by world leaders at the Paris Climate Change Conference in Paris (COP 2130 November 11 December 2015) gives rise to hope that action will be taken towards a sustainable future. But there is not one single way to fix the climate. The challenges look differently to people in the streets of Beijing, in the townships of Johannesburg, and in the cornfields of Kansas. What we offer in this manifesto is a clear identification of exactly what the humanities may contribute to understanding of human imagination, perception and relationship with their surrounding environments - both social and natural. For a start humanities disciplines are wonderfully diverse, both in terms of methodologies and interests - a reflection of the ever-expanding experience of the human species itself. Curiosity spawns diversity in the humanities, as in all other academic pursuits, and curiosity is the very fuel of humanities research. On the other hand, in order to achieve economies of scale and impact, humanists need a concentration of effort and clarity of focus. Our manifesto identifies five key questions in the global change agenda that call for clear humanities answers. Such questions require basic research, and the answers will be of direct relevance to stakeholders in the societal, cultural, economic, political, and academic worlds. 


\section{A Research Agenda for Global Observatories}

\subsection{What Is Happening?}

Historical investigations have identified a "Great Acceleration" of human technologies, powers and consumption in the last 70 years that has operated as a key driver of Global Change [3,4]. These human advances have come with an alteration of the planet's carbon and nitrogen cycles, rapidly rising species extinction rates, and the generation of atmospheric greenhouse gases, which in turn are catalysts for adverse weather patterns and increased ocean acidification, the consequences of which will condition life on the planet for centuries to come. At the same time nuclear bombs have enabled us both to destroy human lives and to leave enduring markers on the planet. Scientists are increasingly labeling this period as the beginning of the Anthropocene epoch. This neologism, meaning "Age of Man", or "Age of the Human" was proposed in a short essay by Paul Crutzen, a Nobel-prize winning geologist, and Eugene Stoermer, an atmospheric chemist, to designate a new post-Holocene epoch marked by anthropogenic impacts on the earth system $[5,6]$.

In the decade and a half since the publication of Crutzen and Stoermer's essay, scholars from across the disciplines have flocked into symposia and conferences to discuss and debate what cultural critic Rob Nixon has called this "epochal idea" [1]. While the original framework of thought of the Anthropocene was led for the most part by natural scientists, it resonated with what was already by the 1990s emerging as a new field that would eventually be called the "environmental humanities". Once divided humanities sub-disciplines such as history, philosophy, religious studies, and literature, and social science disciplines focused on humans-in-their-environments, such as anthropology, cultural geography, and political ecology, began flowing together [2,7-9]. Without abandoning the subject-matter strengths and specific tools that are the hallmark of their discipline, humanists began reimagining "the proper questions and approaches" of their fields in light of environmental challenges [10]. While this reorientation is still ongoing, we believe it is possible to discern some research questions that extend beyond planetary measurements to include surveys and measurements of the drivers of human society.

The Great Acceleration argument, in particular, is premised on the impact of social, economic and cultural developments as much as it is on scientifically registered environmental changes. It is therefore incumbent on historians, archaeologists, anthropologists, and other humanities disciplines that study change through human time to assess and improve both our measurements and our understandings of the driving forces. While the Great Acceleration may be a global phenomenon, it has taken place at different rates and in very different contexts around the globe. We thus need to refine and adjust the historical interpretation accordingly - and to refine the global picture by taking into account regional and local factors. For example, the humanities can offer unique insights into this acceleration by studying and reflecting on variations in renewable energy use, the willingness and ability of different societies to adopt renewable energy sources, and the political, institutional, cultural, and cognitive factors that shape the implementation and use of different sources of energy.

\subsection{What Prevents Us from Pro-Environmental Action?}

Environmental science measures and informs us of the scale of change. Science does not necessarily, however, make us or help us to change direction. At the heart of global change in the $21 \mathrm{st}$ 
century lie human choices and actions - questions of human behavior, preference and motivation that are imbedded in individual practices and actions, in institutional and cultural pathways, and in political strategies. Human choices, we know, are hardly ever fully conscious: we often prefer to tread well-known paths rather than explore new possibilities. Prior investments and institutional interests may even bar us from taking a preferred option. Frequently, too, we choose actions, pathways and strategies based on limited perspectives and knowledge, and in circumstances when we may not be cognitively prepared to identify optimal solutions to a challenge.

Unfortunately, intellectual and cultural enlightenment does not necessarily lead to changes in human behavior. Science has discovered, to its despair, that new accretions of information may have no impact and that laying out a set of rational choices may not lead to action. Indeed, scientific understandings of the physical world may be of limited use for understanding the complexity and volatility of human values and motivations. While the sciences may observe and analyze change, they are not organized or structured to create social policy and influence humans to change values and opinions. The human sciences - the mixed bag of academic disciplines in the humanities - are, on the other hand, a fertile and largely untapped resource of insight into human motivation, creativity, and agency.

Human beings use language, narrative, imagination and cognitive models to understand, cope, and take action. We nourish values and ethics to guide our choices. These tools and yardsticks are what the humanities help us to understand and use. Humanities disciplines are repositories of insight into human perception, motivation, creativity, and agency at a variety of levels-individual, institutional and social. For example, Anja Kollmuss and Julian Agyeman [11] view environmental knowledge, values, and attitudes, together with emotional attachment, as making up a complex called "pro-environmental consciousness." They argue that concomitant environmental values, beliefs and expectations are expressed in actions, including political activism, technological optimism, or individual retreat, with consequences that ramify from local to the global levels. Humanities insights, therefore, may help us transform our perceptions and imaginations.

We need to define and understand how and why, in the face of non-imminent or non-palpable danger, humans choose to act as we do and what it would take to make us change direction. Our research questions must function at individual, institutional, and social levels: How do individuals respond to calls for change in individual or collective behavior? How can social innovation help redress institutionally ingrained patterns and path dependencies? And how do societies develop resilient responses to threats of crisis and collapse? These questions defy both rational choice theory and behavioral decision theory because human actions operating within such broad frameworks encounter numbers of emotional and mental stumbling blocks to concerted pro-environmental action.

The most immediate challenge is the well-known "Prisoner's Dilemma". We would all benefit from collaboration towards the common good, but in an open system with a free market, weak global politics, cultural distrust, and imperfect communications, defectors are likely to get away with cheating. The only solution to overcome the Prisoner's Dilemma is mutual trust, yet polities are rarely able to make this choice. Trust relies on insight into past behavior and cultural preferences, which can be furthered by means of historical investigation, discourse analysis, and philosophical disentanglement. Conflict resolution relies on such insights.

A second stumbling block is the problem of unintended consequences. When societies do take positive action, they often find that their responses are too limited or open up wicked problems - problems, 
which by their nature defy complete and clear solutions. When we address one or more sides of an issue, other aspects can be aggravated and new aspects that we did not foresee can turn up, generating results that nobody wanted. Wicked problems often include both natural resource issues and human responses to these, such as war and migration. The heterogeneous nature of the challenges confronting us also proliferate a new set of problems that arise when solutions are implemented in haste. This in turn causes unforeseen consequences and additional dilemmas, which must then also be remedied. Human behavior, preference, creativity, and motivation, imbedded in individual action, institutional and cultural pathways and political strategies, stand at the heart of these problems. The humanities, however, can help elucidate and point to ways out of wicked problems.

Thirdly, even when we know the right course, we may not actually take it. Humans struggle to change harmful habits, repetitive actions, or unhealthy preferences (path dependencies) even when they clearly recognize the negative consequences of inaction. The problem of "acrasia" (often defined as weakness of will) has troubled philosophers since ancient times. While Socrates held that no one would knowingly go towards the bad, Aristotle asserted, more realistically, that opinions may or may not reflect the good - and that opinions may be contradicted by bodily appetites. The problem of giving up smoking is an obvious example at the individual level, just as the problem of decarbonization may be at a societal level: institutionalized interest may deter us from choosing what we would otherwise perceive to be in our best interest. Psychologists and philosophers can provide unique insights into such conundrums, and close studies of change behavior and "tipping points" in the past can render useful insights for the future.

Fourthly, time may work against our best interests. Hyperbolic discounting means that our judgments may vary depending on whether we are close to a reward or further from it. Action now may promise high returns in decades to come, but the immediate cost may deter us. Discounting is often perceived as an economic problem, and much ink has been spilt on debating the rate of discount at the decadal to centennial scale. A high rate of discount will tend to minimize future problems and increase incentives to prioritize investment for immediate needs, while a low discount prioritizes the future in favor of the present. Valuation studies are notoriously more precise the closer in time the choice is to be made, and the more the choice is of monetary value. Non-monetary valuation is potentially a big, though presently underdeveloped, field for the humanities. How, for example, might the humanities help develop valuation over and above willingness-to-pay so that rigorous cultural valuation schemes can be put in place? Ethics should be a front-runner in developing such studies, but it needs also to be informed by understandings of time, discounting, technology and nature, and by differences in pro-social behavior in, e.g., common-property resource dilemmas.

Fifthly, linguistic and cultural barriers exacerbate all the problems we have outlined. What one culture considers positive civic behavior may not be accepted by another, and what is understood by correct behavior in one language may not have its equivalent in another. What one culture deems a crucial problem or issue may be nothing of consequence to another culture. Clearly, not all humans have contributed equally to the new conditions in which we live. The authors of this paper believe strongly in the benefits of learning from the diversity of human experiences, knowledge systems, and perceptions. Loss of cultural diversity is a cancerous process very similar to the loss of natural biodiversity. While the loss of one spoken language, or of a particular heritage site, or of an immaterial practice will not ruin the world, systematic disregard for historical and cultural heritage reduces our 
insight into the diversity of human experience and diminishes our collective intelligence. The humanities thus need to work with the natural sciences to articulate and understand the value of human as well as natural diversity.

Individually the problems identified above are well known, but they are often disregarded in environmental studies and its associated policy outcomes. The humanities can intervene by emphasizing and working on these and other barriers and by engaging in alternative and counterfactual scenario building. Philosophy frames ethical and moral agendas by juxtaposing principles and concepts such as morality (altruism) and prudence (self-interest); cosmopolitanism and diversity; expert and non-expert and top/down and bottom/up considerations. Psychology and other fields, offer increasing evidence that people rely on their imaginations and construct counterfactual situations and alternative possibilities in order to overcome the constraints of limited avenues of action and thought [12]. There are strikingly familiar and regular fault lines in human cognition that provide logic and coherence to the imagination. People tend to change things within their control-and to focus on the things they can control. By exploring the spectrum of the human imagination-from the mundane, everyday imagination to daydreams and fantasy - counterfactual thinking helps us how to think about the future in hypothetical ways, and can provide a key to addressing human issues of consciousness, perception, and agency.

\subsection{What Do We Think of the New Human Condition?}

The concept of the Anthropocene is now commonly used by scholars to denote a distinct new geological and biophysical epoch, which can be either violent and extreme or slow, stealthy and subversive and which will last for centuries and possibly millennia. In order to focus on the overarching challenge to humanity from our own preferences and actions, however, we suggest that it might be useful to borrow a fresh concept from the European HfE Observatory, "the New Human Condition", in order to identify the particular challenges of the 21 st century [8]. This term reflects the humanities' focus on much shorter time scales and with greater urgencies of perception and action. The New Human Condition refers to the unprecedented crisis of how we as a species will cope with the consequences, not to mention responsibilities, of being the major driver of planetary change. Our human intelligence has given us the power to create as well as to destroy the foundations of our own existence. The idea of the New Human Condition therefore raises pressing questions about Human Intelligence. Are we able to learn and steer our course through global change, or is our future predicated on a pattern of relentless exploitation of nature and of unchecked demographic growth? These are challenges to civic action, as well as to global governance of an entirely new order when compared to previous human epochs. The New Human Condition might indeed be the biggest cognitive challenge to human intelligence in history. Thus, the research question we must confront is how to identify, respond to and cope with the consequences of the New Human Condition.

Public responses to this question range from denial to despair, and from alarmism to instinctual belief in our ability to cope. News of tragedy, disaster and pending doom travels fast in our connected world, while positive action and amelioration seems less likely or more naïve. However, paradoxically, cultures of alarmism and denial go hand in hand. Some cry wolf; others deny the footprint. As the human species becomes ever more technologically powerful, many doubt its fitness to govern the 
world that it has created. Collapse is the title of a hugely influential book by the American ecologist and geographer Jared Diamond [13], who speaks to a world fascinated by doom and an inability to correct a disastrous trajectory. A more optimistic approach, however, is taken by leading proponents of the theory of the Anthropocene, such as Paul Crutzen and Eugene Stoermer [5], as well as Paul R. Ehrlich and Anne H. Ehrlich [14], all of whom declare a belief in human intelligence. Some advise cutting back emissions and extractions to a "safe operating space" [15] and others detect a long-term rebound of nature by current trends in dematerialization and decarbonization [16]. While these authors are all scientists, similar debates have emerged among environmental humanists. Many environmental historians for example identify a declensionist trajectory of human interaction with nature that would seem to support the Diamond view. On the other hand, critics of Diamond point out that while empires may collapse, humans do not, and have managed successfully to reorganize themselves in extremely adverse times [17].

Research into how we have identified and dealt with challenges in the past may also help to clarify our ability to cope in the present and future. Historians, literary scholars, and philosophers, to name just a few disciplines, are particularly well qualified to take on this question. The Stern report on the Economics of Climate Change [18] argued, for example, that humanity has the technical knowhow at hand to mitigate climate change. However, nine years after the review was published, the world seems, if anything, more divided, uncertain and incapable of dealing with the issues of the global environment. While a rational choice approach to such a conundrum may lead one to despair, media studies, political science inquiries and comparative studies focused on the long-term run of public inquiries may provide a different, and perhaps more optimistic, interpretation. Another recent historical example also suggests that not all is worsening. Despite overall ocean deterioration, we have seen improvements in the health of major commercial fish species as a result of better management and consumer preference for sustainably sourced food [19]. Another positive example is the success of combined public communication and policies in combating tobacco use, as well as the AIDS/HIV epidemic - even across cultural divides [20]. We evidently stand to learn much about human behavior at individual, institutional and societal scales by undertaking closer analysis. These examples also indicate that decisive change can occur within the short timespan of years or decades, an encouragingly swift result for human induced action.

As a species, we are probably hard-wired to believe in our own capacities, and in the interest of one's own sanity it may be advisable to try to retain hope, even if with some caution. It makes sense, therefore, for us to seek examples of human action at the individual, institutional or societal levels that demonstrate our capacity to change direction on receipt of warning. Can humans change tack in a more proactive way not just when confronted with immediate disaster but also when faced with a long-term threat or a slippery slope? The question is not if, but when and how successfully, we can respond to global challenges. Can we learn from past challenges of resource scarcity and long-term degradation? Some third world countries and indigenous groups are leading strongly on the issue of climate change, not waiting for first world countries to act, and thus they are suggesting something of a higher "human intelligence" than some first world countries, at least on the issue of climate change [21]. We advance therefore the notion and limitations of Global Human Intelligence as a guiding research question. 


\subsection{What Can the Humanities Do?}

Although good examples of interdisciplinary research exist, most of us are simply not organized to deal with the scale and complexity of global change issues. Collaboration across faculty divides is structurally and culturally difficult, and happens infrequently [22]. Humanities skills are rarely utilized for strategic change, and humanities academics are also often reluctant to position themselves in this way. Proponents of interdisciplinary research across the science and technology sectors tend to relegate human and social science research to an auxiliary, advisory, and non-essential status.

Critics also often claim that humanists complicate rather than simplify solutions, and there is some truth to this. However, the world is unquestionably a complicated place. While foggy responses do not help anyone, neither do simplistic approaches. Helga Nowotny [23] notes that the "quest for relevance in the social sciences triumphed during the mid-twentieth century, celebrating planning, social engineering and foresight. Its latest embodiment is the belief in evidence-based policy." Yet, states Nowotny, "it is often difficult to discern which kind of evidence counts in a given situation, whose evidence is to be used, and for what purpose." She concludes that shifting from relevant knowledge to socially robust knowledge includes employing multiple, even contradictory, perspectives. This view coincides with the United Nations Development Program Foresight Manual, which observes that goals must be "realised in uncertain and unpredictable environments, in which 'black swans' feature prominently, and over which authorities have less, little or no control" [24].

The humanities commonly deal with contradictory things, another source of their value in responding to the wicked problems of social and environmental change. Experience suggests that there is initial mistrust when humanities, social science, and scientific analyses are integrated to address wicked problems, however, as the process begins to generate solutions, cross-disciplinary engagements proliferate in numbers and regard. Specifically, environmental humanities scholars and scientists need to work together to understand cultural differences, to overcome stock prejudices, to understand the importance of affect and multiple perspectives — and to instigate actions as well.

Like most other researchers, humanities scholars see their role primarily as analytical rather than prescriptive, and tend to worry that scholarly curiosity and cherished analytical methods may be contaminated by strategic concerns that override open investigation. Indeed, most academics would fear that their academic credentials were potentially compromised by activism. This disconnect between thought and action is a conundrum which must be overcome if the abstract call on the humanities to inform global change is to be turned into practice. A middle ground between contemplative research and positive action would be to see the Global Change agenda as a strategic change process, which requires vision, skills, incentives, resources and a plan [25]. Each of these factors can benefit from humanities skills. A vision for climate change adaptation that fails to include cultural preferences can only lead to confusion or opposition. Identifying the right incentives, however, is often tricky because market-driven performance indicators are seldom the only drivers of human preference. Frustration or a false start may result when the right resources or a balanced plan are not identified. Therefore, we need to ask:

- who and what are the drivers of change

- what is happening

- what can be done 
- how to get it done

- and what are the means to do it

Analytical questions of this kind are in no way inimical to academic practice, but should be central to the mission of the environmental humanities.

\subsection{How to Get It Done}

If the humanities are to help make the world a better place, we need to do our research and also to translate it into practical use. We are suffering both from lack of knowledge and from poor knowledge pathways. The humanities have a wonderful record of turning research into accessible books, TV productions and museum displays. However, our record of turning insights into political advice and business propositions is less impressive.

True, the problem of translation of knowledge into empowerment is by no means confined to the humanities, and is certainly shared with the natural sciences. However, this problem needs to be addressed directly, and we in the humanities have both good advice to offer and lessons to learn. The humanities have considerable experience in reaching out to the public through established channels, which are already being put to good use. This is a unique strength, and one that our Observatories should highlight and propagate. Engaging with politics directly is of course much more conflicted. Again, many humanists have engaged in the lobbying and criticism of politicians, but with mixed results. Humanists working in some museums and media have done wonderful work. There is room for improvement here - perhaps by facilitating dialogue between citizens and politicians in the manner practiced by many humanities centers and by our Observatories in the past two years.

We want to emphasize the capacity of the humanities to move beyond models of research that locate the formation of knowledge exclusively within the academy. It seems to us that what we need, and what many humanists are well equipped to do, is to develop collaborative processes of conversation and knowledge engagement that are shared by academics and publics, as well as other stakeholders such as policy bodies etc. We know that human action in relation to information relies on a sense of investment in and ownership over knowledge; the sense that knowledge connects organically with current modes of understanding. This means that we need to think about "people" not just as objects of research but also equally as participants in producing knowledge. We must acknowledge that not all useful knowledge from an environmental perspective is located within the academy. We need not only to know more about how and why humans act, but also new ways of building knowledge. The humanities (academic and public) are well placed to take up this work.

Further, and perhaps most importantly, the humanities need to engage much more broadly with business. Business can bring insights into customer behavior and has the ability to engage and execute actions. Businesses are concerned about public image, as well as ways of feeding back to society, and are often willing to sponsor environmental exhibitions, tours, teach-ins, and activities, not to mention related academic work and publications and broadcasts. More importantly, businesses - not least insurance companies - are concerned with their long-term sustainability and are increasingly taking on board the necessity to plan for and cope in a changing environment. Multinational companies operate on politically sensitive global markets where they have to be at the forefront of both political and technological mega-trends. They are used to being user-centric and to adapt quickly. Additionally, 
there is a growing tendency for Corporate Social Responsibility to be a fully integrated part of a business model. Potentially, there is a strong synergy in combining humanistic knowledge of human behavior, cultures and religion in a global context with companies that are used to operate quickly and efficiently in hundreds of different market places and turning decisions into action.

Finally, breakthroughs in humanities computing and the uses of Big Data offer new and exciting ways of mapping and understanding human perception and behavior. There is no shortage of data whatsoever. At the same time the technology threshold is being dramatically lowered in every aspect every six months or so, and this trend will just accelerate in the future. The Humanities' access to new tools and a genuine capability of pulling off advanced scenario-building and text analytics constitutes a great potential for analyzing both hard facts and soft values like behavior and social networks [26].

\section{What We Have Done so Far}

Each of the existing Observatories has devoted the past two years to testing and experimenting with innovative models for how the humanities can be energized for the environment. In 2014 principal investigators and key researchers working on the Humanities for the Environment project drafted a set of shared ideas, or "Common Threads", that has guided research in what they provisionally termed the "Anthropocene Humanities". Although each Observatory would innovate its own distinct programming, audiences, methods, practices and arguments, projects would be connected by a common aim to alert and educate multiple and widening publics-including policy makers and community members - to the extraordinary biophysical effects of human activities that are "transforming the chemical, physical and biological processes of the Earth's atmosphere, land surfaces and oceans at an ever-increasing pace". A common website was developed by the team at Wake Forest University and is now maintained by Arizona State University [27].

The European Observatory focused its work in the past two years on developing a dialogue between academics and senior executives in large corporations and NGOs. Their agenda was to try out in a series of workshops how and to what extent humanities insights might resonate with and impact corporate and civic action. The workshops have helped identify the unique capabilities of different humanistic disciplines and methodologies and how they may address environmental change. A forthcoming special issue of a peer-reviewed journal will publish the findings of the workshops.

The Australian/Pacific Observatory has adopted multiple strategies. They have developed and worked in formal collaborations with business organizations, with indigenous lobby groups, with art and museum collectives, with NGOs such as Greenpeace, Future Earth and the Oceans Conservation Foundation, with City governments in Sydney and Melbourne, and with representative scholarly bodies such as the Chief Scientist's Office and the Australian Academy of the Humanities.

The North American Observatory is rethinking the relationships of human beings and knowledge systems to one another, to other species, and to ecological systems in the Anthropocene. Under the thematic framework "Building Resilience in the Anthropocene", this Observatory convened three workshops to bring together academic, professional, and public knowledge communities (including indigenous communities) to focus on intertwined environmental and social justice challenges, such as the future of food systems, wildlife conservation programs, water systems, and waste disposal in ten communities in America, Canada and Nepal, and to plan for a more adaptive and resilient future 
guided by sustainability and social justice principles and values. A forthcoming special issue of a peer-reviewed journal will publish the findings and report on the project that emerged from these workshops.

New Observatories for East Asia, Asia-Pacific, and Africa are in a formative stage. The East Asia Observatory's mission, "Rethinking Nurture and Renewing Nature in the Anthropocene", enlists the humanities and related disciplines to join the fray in confronting the serious environmental and climate problems of the new century. The National Taiwan University leading the East Asia Observatory is focused on regional agricultural ethics, co-hosting a conference on Food Ethics in East Asian Perspective (October 2015). NTU will develop a digital platform as an entry point to information on the evolving state of the environment in East Asia and will establish a council to reflect on and discuss "The Uncertain Future" by considering the different futures we might realize. The council will forge ties not only with local academia but also with government units, such as the Taipei mayor's office, which has Design City and Green City initiatives, and with private organizations, such as the American Chamber of Commerce in Taipei, which takes on important civic issues.

The Asia-Pacific Observatory aims to work towards what is calling "the blue humanities", to examine the dynamic and shifting relationship between land and sea in literatures, arts, and other cultural productions. The Asia-Pacific Observatory is funded by the Center for Humanities Innovation and Social Practices (CHISP) of National Sun Yat-sen University and the Humanities Center of National Chung Hsing University, based in Taiwan. The Observatory involves scholars, writers, activists and artists from countries and islands across the Pacific, including China, Guam, Hawaii, Japan, Korea, Okinawa, Taiwan, and North America. The Observatory will offer inputs based on day-to-day realities in the Pacific region to supplement or challenge dominant/hegemonic approaches to imperialism, post-coloniality, indigeneity, and globalization, as well as ecology.

The African Observatory takes as its point of departure the spiritual idea found in a number of indigenous traditional societies in Africa, namely, that human beings are earth keepers rather than earth exploiters. "Earth keeping" does not only provide us with a model for preserving the earth, it is also a form of critique of those local and global practices (especially global capitalism), which have contributed to the degradation of the African environment. The observatory therefore seeks to pay attention to indigenous forms of ecology and how these served to conserve the environment and to create a balanced ecosystem. The Observatory is interested not only in the surviving indigenous practices, but equally in the way new attitudes towards the environment have been shaped by change, leading to a new grammar of framing and speaking about the environment. Any meaningful intervention in Africa's environmental state will have to register a nuanced historical perspective of indigenous and Western/modern ideas of conservation, the rise of the middle class in Africa and its consumerist ideology, the role of digital media for environmental conscience, and the contested roles of food security and government.

\section{What We Propose}

We propose to enlarge our global consortium of HfE Observatories to help implement the outlined agenda in a way that ensures an effective impact. Our Observatories will aim to promote collaborative and comparative research; to develop regional and cultural dialogues for understanding human 
motivation and action in the face of long-term challenges; to build a catalogue of best practices; to develop new cross-disciplinary approaches; and to construct a platform to cater for continuous dialogue with societal stakeholders. The Observatories will observe, explore and implement plans and prescriptions for how the humanistic disciplines can contribute to understanding of and engagement with global change problems by providing crucial insight into human action and motivation.

We also aim to foster a global perspective on the role of the humanities in the Anthropocene. The Global Observatories consortium will sponsor annual workshops, hosted in turn by each global region, as we continue to hone humanities' contributions and outcomes for impact in the public and political arenas. In particular, we will work to ensure that future Intergovernmental Panel of Climate Change (IPCC) reports be informed by humanities' perspectives on the New Human Condition. To foster this aim the Observatories will produce a mid-term regional perspectives report in 2017. The focus of this report will be on regional perspectives of human perception and effective changes of pro-environmental behaviors in relation to such issues as tobacco use, pesticides, chloro-fluoro-carbon (CFC) gasses, HIV/AIDS, same-sex marriages and ethnic/racial and gender equality. These major issues have demonstrated human capacity for a rapid change in moral perspectives and agency at individual, institutional and social levels. The 2017 report will aim to increase our awareness and understanding of human motivation and behavior in environmental contexts and to establish an agenda for future research on global cultural perception and action on climate change, which should inform future IPCC reports.

\section{Conclusions}

We have sketched out a research agenda for environmental humanities and proposed to establish Observatories of Humanities for the Environment across the globe. An expanding HfE network may spur public imagination and draw people from academic, policy and community sectors into conversations and debates about livable futures built on social, technological, and ecological systems agile enough to adapt to weather extremes and changing conditions [9]. As Mike Hulme, a climate scientist who contributed research to the IPCC Reports has observed, framing complex environmental changes as "mega-problems" necessarily demands "mega-solutions" and this "has led us down the wrong road". While Hulme accepts the importance of the scientific work of the IPCC, he suggests that over-reliance on models of scientific expertise that demand "mega-solutions" has resulted in a "political log-jam of gigantic proportions, one that is not only insoluble, but one that is perhaps beyond our comprehension" [28].

Instead, Environmental Humanities should seek a range of evidence-based, reasoned, scaled and culturally diverse responses to the complex problems under examination. We propose a network of projects and publications that address diversity in decision-making processes and pursue multiple potential responses that "are reflective of life in a plural world" where "several actual, probable and possible realities" might be found "relevant to different constituencies" [29]. Environmental Humanities - integrating perspectives from history, literature, philosophy, arts, psychology, sociology and other fields - provides a means to explore the roles of human perception and agency in the face of global climate change. The humanities can help to facilitate an understanding of the complexities of human-environmental relationships, and produce new modes of knowledge necessary to guide global decision-makers. 
As Jacob Bronowski [30] observes, "the world is not a fixed, solid array of objects, out there, for it cannot be fully separated from our perception of it. It shifts under our gaze, it interacts with us, and the knowledge that it yields has to be interpreted by us. There is no way of exchanging information that does not demand an act of judgment." While science offers empirical "certainties" and methodologies capable of measuring the natural phenomena of climate change, the humanities are better adapted to considering multiple decisions, options and solutions based upon social uncertainties and contingencies.

\section{Acknowledgments}

The authors gratefully acknowledge financial support by the Andrew W. Mellon Foundation program Integrating the Humanities Across National Boundaries.

\section{Author Contributions}

Poul Holm drafted the text based on a seminar discussion with Joni Adamson, Hsinya Huang, Sally Kitch, Iain McCalman, James Ogude, Kirill Ole Thompson, Charles Travis and Kirsten Wehner. Lars Kirdan, Marisa Ronan and Dominic Scott contributed additional research. All authors read and approved the final manuscript.

\section{Conflicts of Interest}

The authors declare no conflict of interest.

\section{References}

1. Rob Nixon. "The Anthropocene: The Promise and Pitfalls of an Epochal Idea." Edge Effects, a Project of the Center for Culture, History and Environment. Available online: http://edgeeffects.net/anthropocene-promise-and-pitfalls/ (accessed on 1 October 2015).

2. Rosi Braidotti, Kum Kum Bhavnani, Poul Holm, and Ping-chen Hsiung. "The Humanities and Changing Global Environments." In Changing Global Environments. World Social Science Report. Paris: ISSC, UNESCO, 2013, pp. 506-7.

3. Will Steffen, Regina Angelina Sanderson, Peter D. Tyson, Jill Jäger, Pamela A. Matson, Berrien Moore III, Frank Oldfield, Katherine Richardson, Hans Joachim Schellnhuber, Billie L. Turner, and et al. Global Change and the Earth System: A Planet Under Pressure. Berlin: Springer, 2004.

4. Will Steffen, Wendy Broadgate, Lisa Deutsch, Owen Gaffney, and Cornelia Ludwig. "The trajectory of the Anthropocene: The Great Acceleration.” The Anthropocene Review (2015): 81-98.

5. Paul J. Crutzen, and Eugene F. Stoermer. "The 'Anthropocene'." IGBP Newsletter 41 (2000): 17-18.

6. Jan Zalasiewicz, Mark Williams, and Collin N. Waters. "Anthropocene." In Keywords for Environmental Studies. Edited by Joni Adamson, William A. Gleason and David N. Pellow. New York: New York University Press, 2015.

7. Dipesh Chakrabarty. "The Climate of History.” Critical Inquiry 35 (2009): 197-222.

8. Gísil Pálsson, Carole Crumley, Heide Hackmann, Poul Holm, John Ingram, Alan Kirman, John Marks, Mercedes Pardo Buenída, Sverker Sörlin, and Bronislaw Szerszynski. "Challenges of 
the Anthropocene: Contributions from Social Sciences and Humanities for the Changing Human Condition.” Environmental Science and Policy 28 (2013): 3-13.

9. Joni Adamson. "Humanities." In Keywords for Environmental Studies. Edited by Joni Adamson, William A. Gleason and David N. Pellow. New York: New York University Press, 2015.

10. Deborah Bird Rose, Thom van Dooren, Matthew Chrulew, Stuart Cooke, Matthew Kearnes, and Emily O'Gorman. "Thinking through the Environment, Unsettling the Humanities.” Environmental Humanities 1 (2012): 1-5.

11. Anja Kollmuss, and Julian Agyeman. "Mind the Gap: Why do people act environmentally and what are the barriers to pro-environmental behavior?" Environmental Education Research 8 (2002): 239-60.

12. Ruth M. J. Byrne. "Mental models.” In Emerging Trends in the Social and Behavioral Sciences. Edited by Robert A. Scott and Stephen Michael Kosslyn. Chichester: John Wiley \& Sons, 2015, pp. $1-13$.

13. Jared Diamond. Collapse: How Societies Choose to Fail or Survive. London: Allen Lane, 2005.

14. Paul R. Ehrlich, and Anne H. Ehrlich. "Can a collapse of global civilization be avoided?" Royal Society B 280. Published electronically 9 January 2013. doi: 10.1098/rspb.2012.2845.

15. Johan Rockström, Will Steffen, Kevin Noone, Åsa Persson, F. Stuart Chapin, Eric F. Lambin, Timothy M. Lenton, Marten Scheffer, Carl Folke, and Hans Joachim Schellnhuber, and et al. "A safe operating space for humanity." Nature 461 (2009): 472-75.

16. Jesse H. Ausubel. "Nature Rebounds. Long Now Foundation Seminar." Available online: http://phe.rockefeller.edu/docs/Nature_Rebounds.pdf (accessed on 1 October 2015).

17. Patricia A. McAnany, Norman Yoffee, eds. Questioning Collapse. Human Resilience, Ecological Vulnerability, and the Aftermath of Empire. Cambridge: Cambridge University Press, 2010.

18. Nicholas Herbert Stern. The Economics of Climate Change: The Stern Review. Cambridge: Cambridge University Press, 2007.

19. Seth Atkinson, David Newman, and Lisa Suatoni. "Bringing Back the Fish: An Evaluation of U.S. Fisheries Rebuilding under the Magnuson-Stevens Fishery Conservation and Management Act." NRDC Report R: 13-01-A. Available online: http://www.nrdc.org/oceans/files/rebuildingfisheries-report.pdf (accessed on 1 October 2015).

20. Charles Travis, and Poul Holm. "Lessons for the Anthropocene from the recent past: Tobacco use, HIV/AIDS, and Social Transformation." Global and Planetary Change, forthcoming.

21. World People's Conference. "Climate Change and the Rights of Mother Earth." Available online: http://pwccc.wordpress.com/programa/ (accessed on 1 October 2015).

22. Poul Holm, Michael Evan Goodsite, Sierd Cloetingh, Mauro Agnoletti, Bedrich Moldan, Daniel J. Lang, Rik Leemans, Joergen Oerstroem Moeller, Mercedes Pardo Buendía, and Walter Pohl, and et al. "Collaboration between the Natural, Social and Human Sciences in Global Change Studies.” Environmental Science and Policy 28 (2013): 25-35.

23. Helga Nowotny. "Out of science-Out of sync?" In World Social Science Report. Paris: UNESCO, 2010, pp. 320-21.

24. United Nations Development Program (UNDP). Foresight. The Manual. 2014. Available online: http://www.undp.org/content/dam/undp/library/capacity-development/English/Singapore\%20 Centre/GCPSE_ForesightManual_online.pdf (accessed on 20 December 2015). 
25. Michael Evan Goodsite. "European Experience: European Coalitions Lessons Learned." Available online: http://www.drivecms.com/uploads/appliedsolutions2009.com/ european_experience.michael.goodsite.pdf (accessed on 1 October 2015).

26. Poul Holm, Arne Jarrick, and Dominic Scott. Humanities World Report 2015. London: Palgrave, 2014.

27. Humanities for the Environment. Available online: http://hfe-observatories.org (accessed on 1 October 2015).

28. Mike Hulme. Why We Disagree About Climate Change. Understanding Controversy, Inaction and Opportunity. Cambridge: Cambridge University Press, 2009, pp. 332-33.

29. Noel Castree, William M. Adams, John Barry, Daniel Brockington, Bram Büscher, Esteve Corbera, David Demeritt, Rosaleen Duffy, Ulrike Felt, Katja Neves, and et al. "Changing the Intellectual Climate." Nature Climate Change 4 (2014): 765-66.

30. Jacob Bronowski. The Ascent of Man. London: Futura, 1981, p. 229.

(C) 2015 by the authors; licensee MDPI, Basel, Switzerland. This article is an open access article distributed under the terms and conditions of the Creative Commons Attribution license (http://creativecommons.org/licenses/by/4.0/). 